\title{
Visual working memory in young children
}

\author{
GRAHAM J. HITCH and SEBASTIAN HALLIDAY \\ University of Manchester, Manchester, England \\ and

\begin{abstract}
ALMA M. SCHAAFSTAL and JAN MAARTEN C. SCHRAAGEN
University of Groningen, Groningen, The Netherlands
\end{abstract}

\begin{abstract}
Five experiments investigated immediate memory for drawings of familiar objects in children of different ages. The aims were to demonstrate younger children's greater dependence on visual working memory and to explore the nature of this memory system. Experiment 1 showed that visual similarity of drawings impaired recall in young (5-year-old) children but not in older (10. year-old) children. Experiment 2 showed that younger and older children were affected in contrasting ways when the temporal order of recall was manipulated. Experiment 3 explored a recency effect found in backward recall and investigated its sensitivity to the presentation modality of materials used to produce retroactive interference (RI). For younger children, recency was reduced by visual but not by auditory-verbal RI; for older children, recency was more sensitive to auditoryverbal RI. Experiment 4 confirmed the effect of visual RI on visual recency in young children and showed that the same RI had little effect on their recall of spoken words. These results confirm younger children's dependence on visual working memory. A final experiment showed that the effects of visual similarity and visual RI are additive, suggesting that they reflect different modes of accessing stored visuospatial information. Implications of these findings for developmental issues and for the nature of visual working memory are discussed.
\end{abstract}

Several investigations have suggested that the use of active memorization strategies in immediate memory tasks develops only after children reach an age somewhere between 5 and 7 (see, e.g., Kail, 1984). By far the most commonly studied strategy is subvocal rehearsal. These studies have found that a number of features of performance thought to reflect the use of rehearsal processes are not found in younger children. For example, (1) there is no primacy effect in serial position curves representing 4- and 5-year-olds' memory for a sequence of items (Atkinson, Hansen, \& Bernbach, 1964), although primacy can be induced by teaching such children to rehearse (Kingsley \& Hagen, 1969); (2) there is no tendency for 3- to 5-year-olds' recall to be disrupted when items are phonemically similar, whereas older children show this tendency (Conrad, 1971); and (3) 5- and 6-year-olds, unlike older children, are insensitive to manipulations of the word length of materials and effects of concurrent articulatory suppression (Hitch \& Halliday, 1983).

It is notable that most of the evidence for the development of subvocal rehearsal has come from studies that

Some parts of this research were supported by a grant from the Eco. nomic and Social Research Council to Graham Hitch and Sebastian Halliday. Jan Maarten Schraagen and Alma Schaafstal were visiting students at the University of Manchester and received some support from the Groninger Universiteitsfonds. We are grateful to Janet Littler for technical assistance, to the Manchester schools that gave their cooperation in the experiments, and to Peter Walker, Michael Woodin, and anonymous referees for their helpful comments on the original manuscript. The address for reprints is G. J. Hitch, Department of Psychology, University of Manchester, Manchester M13 9PL, England. have used visually presented materials, such as familiar objects or nameable drawings (see, e.g., Hagen \& Stanovich, 1977), and that little is known about how young, nonrehearsing children remember such materials. In the present study we investigated the hypothesis that these children use some form of visual short-term store (see Hitch \& Halliday, 1983). In doing so, we compared younger and older children's memory for visual materials, and, in addition, we contrasted younger children's memory for visually and auditorily presented materials.

Our second aim in this study was to provide evidence on the nature of visual short-term storage in young children, as a preliminary to understanding more about the adult system. The immature visual memory system can be presumed to be simpler and to present a more tractable problem for investigation. In addition, studies of visual short-term storage in adults have been bedeviled by problems arising from the tendency for verbal memory codes to be used in ostensibly visual tasks (e.g., Cohen \& Granström, 1970). Steps can be taken to avoid contamination of this sort, such as requiring articulatory suppression (e.g., Broadbent \& Broadbent, 1981) or using pattern stimuli that are unlikely to be verbally recoded (e.g., Phillips \& Christie, 1977). However, assessing the effectiveness of such precautions is itself problematic. Against this background, the study of young, nonrehearsing children may offer a useful methodological advantage.

The theoretical framework for the current investigation was provided by the working memory model (Baddeley \& Hitch, 1974), which has been used with some success to account for many aspects of short-term memory in adult 
subjects (Baddeley, 1986). The features of the model that are relevant to this study are as follows: (1) subvocally rehearsed material is stored in a limited-capacity articulatory loop that is sensitive to such variables as word length and phonemic similarity of the items; (2) visual storage is mediated by a separate limited-capacity store; (3) auditorily presented materials enter the articulatory loop directly and automatically, whereas the names of visual materials must first undergo the optional process of articulation (see Baddeley, 1986).

The concept of an articulatory rehearsal loop has proved useful in describing the development of children's shortterm memory abilities. Thus, developmental improvements in overall levels of recall from age 8 onward are closely related to measures of articulation rate, an index of the capacity of the loop (Nicolson, 1981). Furthermore, there is evidence to suggest that younger children's use of the articulatory loop depends critically on the modality in which materials are presented, such that its use for auditory materials emerges earlier than its use for visual materials (Hitch \& Halliday, 1983). Such a difference is consistent with the distinction in the model between visual and auditory modes of accessing the loop, but would require the modification of conventional accounts of the development of rehearsal, which tend to ignore the importance of presentation modality. The model suggested our present hypothesis that young, nonrehearsing children use some form of visual storage to retain visually presented materials. However, we could not use the model to make specific predictions, since we found the relevant experimental methods unsuitable for use with children. We therefore viewed the following experiments as explorations of visual working storage as it appears in children, and not as tests of the working memory model itself.

Some previous research has found that young children's immediate memory for visually presented materials is poorer when the items are visually similar to one another (Brown, 1977; Hayes \& Schulze, 1977), suggesting the involvement of a specifically visual store. Accordingly, the main method of the present investigation was to explore this and other manipulations of visual memory tasks designed to reveal young childrens' use of visual storage. Nameable drawings of familiar objects were thought especially suitable for this purpose, since such stimuli have visual and verbal attributes and can be encoded in a variety of ways. The initial experiments involved comparing immediate memory for drawings in children aged 5 and 10 , ages thought likely to straddle the period in which verbal rehearsal strategies undergo their major development. The first study reexamined the effect of visual similarity on recall, using a more satisfactory procedure than those used in previous investigations.

\section{EXPERIMENT 1}

A general methodological problem in the interpretation of effects of visual similarity on memory for visually presented materials is that such effects may arise from confusions among items at registration. Therefore, they do not strongly imply the use of visual representations in memory storage. This problem is especially important in studies of young children, for whom perceptual skills may not be fully developed. To control for this, the studies carried out by Brown (1977) and by Hayes and Schulze (1977) included a check on the children's ability to identify the visually similar items. However, a weakness of these studies was that perceptual identification was assessed under conditions of zero memory load. Registration errors would, of course, be expected to be more likely in the presence of the additional memory load associated with the requirement to remember. In Experiment 1, therefore, we sought to reassess the effect of visual similarity, and to include a control for the children's ability to identify the items during memorization itself. This was achieved straightforwardly by assessing identification accuracy in a version of the memory task in which children were required to name the items at presentation. Word length of the names of the items was also manipulated in order to assess the role of speech-based encoding.

Thus groups of 5- and 10-year-olds were tested on immediate memory for three sets of drawings of familiar objects: a visually similar set, a set with long names, and a control set. In the main task, the children were required to remain silent during presentation to avoid any effects associated with overt speech. It was predicted that 5-yearolds would remember fewer of the visually similar materials, but would be unaffected by the manipulation of word length. Older children, who tend to rehearse the materials using the speech-based articulatory loop, were expected to remember fewer of the materials with longer names, in accordance with our previous findings (Hitch \& Halliday, 1983). It is of some interest whether these older children would also be sensitive to visual similarity. If so, it would suggest that development involves an increase in the number of ways visual materials are encoded. If not, it might suggest a developmental switch from one form of encoding to another.

\section{Method}

Subjects. There were 54 subjects from primary schools located in a middle-class Manchester suburb. Eighteen ( 9 male, 9 female) subjects formed a 10-year-old group. Their average age was 10,6 (range 10,2-11,1). Thirty-six (20 male, 16 female) subjects formed a 5-year-old group. Their average age was 5,6 (range 5,0-6,0). The 5-year-olds were allocated to two subgroups, approximately balanced by age and sex.

Materials. Three sets of eight line drawings of common objects were used throughout the experiment (see Figure 1 for examples). They were adapted from published materials, such as the Peabody Picture Vocabulary Test (Dunn, 1965). The names of the items were matched for frequency of use, as measured by the mean of their frequencies in third- and fourth-grade reading materials (Carroll, Davies, \& Richman, 1971). The control set comprised pictures of a doll, bath, glove, spoon, belt, cake, leaf, and pig. These drawings were not visually similar, and the names of the objects were monosyllabic words. The visually similar set consisted of pictures of a nail, bat, key, spade, comb, saw, fork, and pen. In this set the items also had monsyllabic names but were long objects, each drawn with its major axis in the same oblique orientation as the 


\section{CONTROL}

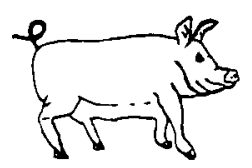

(pig)

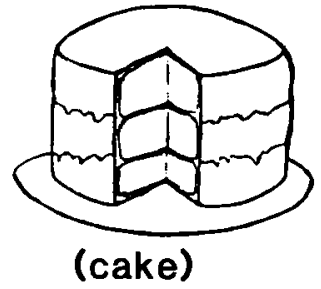

VISUALLY SIMILAR
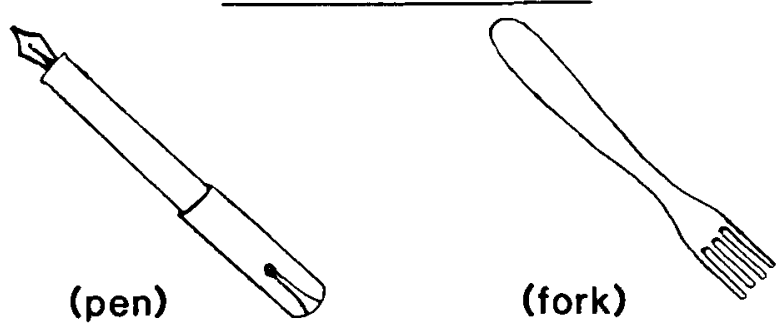

(fork)

\section{LONG NAMES}

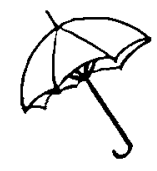

(umbrella)

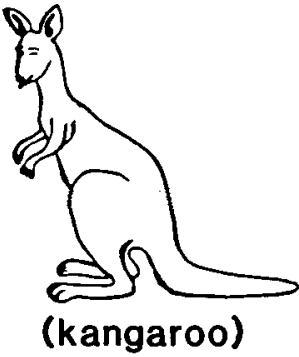

Figure 1. Examples of drawings used in Experiment 1 (redrawn from Dunn, 1965).

others. The long-name set consisted of pictures of visually dissimilar objects with three-syllable names: elephant, kangaroo, aeroplane, banana, piano, policeman, butterfly, and umbrella. A fourth set of drawings--dog, chair, star, cup, gun, and ball-was used for practice. An audiovisual metronome was used to control the rate of presentation.

Design. Different list lengths were presented to each age group to avoid the presence of floor or ceiling effects. Five-year-olds and 10-year-olds were given sequences of three and five drawings, respectively.

Type of materials was a within-subjects variable. Each subject was assigned a block of six lists for each type of material. The order of presentation of the blocks was rotated factorially across subjects. Each list was constructed by random sampling without replacement from the relevant pool of materials. Different lists were constructed for each subject.

One group of 5-year-olds was assigned to the experimental condition involving silent presentation. The other was assigned to the control condition in which drawings were named aloud at presentation. The 10-year-olds were run only in the experimental condition.

Procedure. The children sat at a small table and were tested individually. They were first asked to name each of the drawings in the practice set. Any failures to give the designated name were corrected and retested. The children were then given practice in the procedure for the recall task. This involved short, relatively easy sequences comprising two items for the 5-year-olds and three for the 10-year-olds. Each drawing was shown face up and then turned face down at a separate location in a horizontal row; the presenta- tion rate was one item per $2 \mathrm{sec}$. The children were instructed that they would have to repeat the names of the pictures in the same order as they were shown. Children in the 5-year-old control group were required to name each item aloud as it was shown; those in the experimental groups were required to remain silent. Recall was prompted by the experimenter, who pointed to each overturned card in turn and asked the child to name it. After the first one or two trials, the verbal component of the prompt was omitted. Children were allowed to say "don't know" if they were unsure of the correct response. Training was terminated when recall was accurate on two consecutive trials.

In the main part of the experiment, the above procedure was repeated in its entirety for each of the three blocks of experimental materials in turn, except that sequence length was now three for the 5-year-olds and five for the 10-year-olds. Each child was given six trials in each block.

For the 10-year-olds, all the testing was carried out in a single session lasting about $20 \mathrm{~min}$. To ensure that the 5-year-olds remained attentive, they were tested in two sessions on consecutive days. The first consisted of initial training followed by one block of memory trials, the second a short retraining followed by the remaining blocks of memory trials. Each of these sessions lasted about $10 \mathrm{~min}$.

\section{Results}

Recall was scored as the number of items in the correct serial order on each trial. Table 1 summarizes the recall performance of the two experimental groups. Because 5- and 10-year-olds received different list lengths, it was considered appropriate to conduct separate statistical analyses.

The 10-year-olds found the drawings with long names harder to recall than those with short (control) names $[t(17)=5.07, p<.01]$, but were insensitive to visual similarity $[t(17)<1]$. The 5 -year-olds were disrupted by visual similarity $[t(17)=5.87, p<.01]$, and also showed a small effect of name length $[t(17)=2.03$, $p<.05]$.

Data from the 5-year-old control group were inspected for errors of naming during sequence presentation. Naming performance was completely accurate except for one error by one child on one occasion. Although not of direct relevance to the experimental hypotheses, the recall data from this group are also shown in the table. Naming at presentation led to an overall improvement in recall: Although there was no significant effect of name length

Table 1

Mean Numbers of Items Correctly Recalled and Standard Deviations as a Function of Materials for 5-Year-Olds and 10-Year-Olds

\begin{tabular}{|c|c|c|c|c|c|c|c|}
\hline \multirow[b]{3}{*}{ Age Group } & \multirow[b]{3}{*}{$n$} & \multicolumn{6}{|c|}{ Type of Materials } \\
\hline & & \multicolumn{2}{|c|}{ Control } & \multicolumn{2}{|c|}{ Visually Similar } & \multicolumn{2}{|c|}{ Long Names } \\
\hline & & $M$ & $S D$ & $M$ & $S D$ & $M$ & $S D$ \\
\hline \multicolumn{8}{|c|}{ Experimental Groups } \\
\hline $\begin{array}{l}\text { 5-Year-Olds } \\
10 \text {-Year-Olds }\end{array}$ & $\begin{array}{l}18 \\
18\end{array}$ & $\begin{array}{l}2.07 \\
3.68\end{array}$ & $\begin{array}{l}0.49 \\
0.59\end{array}$ & $\begin{array}{l}1.40 \\
3.61\end{array}$ & $\begin{array}{l}0.62 \\
0.75\end{array}$ & $\begin{array}{l}1.76 \\
2.81\end{array}$ & $\begin{array}{l}0.70 \\
0.76\end{array}$ \\
\hline \multicolumn{8}{|c|}{ Control Group } \\
\hline 5-Year-Olds & 18 & 2.69 & 0.29 & 2.46 & 0.53 & 2.59 & 0.39 \\
\hline
\end{tabular}

Note-The maximum possible scores for 5-year-olds and 10-year-olds were 3 and 5 , respectively. 
$[t(17)=1.21]$, visual similarity continued to lead to a detectable, albeit slight, impairment in recall $[t(17)=$ $2.18, p<.05]$.

\section{Discussion}

The recall results are consistent with the earlier demonstrations of young children's sensivity to visual similarity of the materials (Brown, 1977; Hayes \& Schulze, 1977). Moreover, since there were virtually no identification errors by children in the control condition, despite the requirement to memorize, the effect can be attributed to memory rather than registration. We therefore conclude that young children do indeed use visual working memory to store visual materials. The presence of a visual similarity effect in the control condition suggests that some reliance on visual coding persists even when an auditoryverbal code is made explicitly available at presentation. Evidently, the tendency for young children to use visual working memory is pervasive. However, it seems that the younger children in the present experiment were not entirely reliant on visual storage, because they also showed some sensitivity to the word length of the names of the drawings. We infer that at least some of the children had acquired the subvocal rehearsal strategy earlier than we had anticipated on the basis of previous findings.

It appears from these results that visual working memory stores such characteristics of objects as their shape, orientation, and detailed appearance. A possible mechanism for the visual similarity effect follows Conrad's $(1965,1967)$ model of the effects of phonemic similarity. This model maintains that, during recall, subjects examine partially forgotten traces and attempt to reconstruct what each item must have been on the basis of the information that remains. In a system storing visual characteristics, reconstruction of this sort would obviously be more difficult for items sharing common visual features than for dissimilar items.

The older children showed a marked sensitivity to the length of the names of the drawings, consistent with previous findings (Hitch \& Halliday, 1983) and suggesting that they were actively rehearsing the names. The absence of a visual similarity effect in older children suggests that the tendency to use visual working memory may become less pervasive as development proceeds.

Experiment 2 attempted to confirm these age differences in encoding by investigating the effect of a further, independent manipulation on younger and older children's ability to recall.

\section{EXPERIMENT 2}

This experiment investigated the role of temporal factors in memory for spatiotemporal sequences of drawings in children of different ages. It was assumed that storage involving subvocal rehearsal of the names of the drawings would imply a predominantly temporal-sequential organization. Alternatively, use of visual working memory would involve predominantly spatial organization. Previ- ous work using this type of logic, summarized by O'Connor and Hermelin (1978), has been successful in demonstrating encoding differences between deaf and hearing children. In one of their experiments ( $O^{\prime}$ Connor \& Hermelin, 1976), 14-year-old hearing children showed poorer backward recall of visually presented letter sequences than deaf children of the same age. This is consistent with a greater use of sequential rehearsal in the hearing children, which created difficulty in reversing the stored temporal order. We therefore compared forward and backward recall in 5- and 10-year-old children, predicting an increase in the relative difficulty of backward recall in the older group. The recall conditions were randomized from trial to trial to prevent the children from systematically varying their encoding strategies.

We also planned to examine serial position curves for evidence of primacy and recency effects that might shed light on any effects of order of report. Previous work on children's memory for visual materials has shown that there is a primacy effect only in older children but that a recency effect is found in both older and younger children (Hagen \& Kail, 1973). As mentioned above, primacy has frequently been attributed to rehearsal processes. Recency, on the other hand, has been taken to reflect the operation of an ordinal retrieval strategy applied to a passive store (see Hitch, 1980). Backward recall maximizes the contribution of recency to performance, because the forward order of report gives rise to output interference from the subject's own responses. Thus, it seemed possible that younger children may actually recall more in the backward report order than in the forward one.

\section{Method}

Subjects. The young group consisted of 24 children (13 boys and 11 girls), whose ages ranged from 4,10 to $5,11(M=5.2)$. The older group contained 24 children ( 9 boys and 15 girls), whose ages ranged from 10,3 to $11,3(M=10,9)$. Approximately half the children in each group were from a primary school near the center of Manchester; the remainder were from two primary schools located in middle-class suburbs.

Materials. The drawings that had formed the control set in Experiment 1 were used throughout the experiment. Initial training utilized the same, separate set of practice items used previously.

Design. The young and older children were given sequences of three and five items, respectively. Sequences contained no repeated items and were individually randomized for each child. There were 12 trials, 6 with forward recall and 6 with backward, arranged in a different quasirandom order for each child. The same order of conditions for a child in one age group was used for a corresponding child in the other.

Procedure. Details of the procedure were the same as in Experiment 1 except for changes to the instructions, the testing protocol, and the amount of preliminary training. The children were told that they would see a series of cards, each of which would be shown face up and then turned face down. Immediately following presentation, their task was to name each overturned card from memory as the experimenter pointed to it. The cards were placed in a column pointing vertically away from the child, from bottom to top. On forward recall trials, the experimenter pointed to the cards in their order of presentation; on backward trials, pointing was in the reverse order, beginning with the one shown last. The children were not told in advance which recall order would be requested on any trial. 
There were four preliminary training trials using shorter sequences, two for each order of recall. The experimental session lasted approximately $15 \mathrm{~min}$.

\section{Results}

Performance was scored as the proportion of items correctly recalled at each serial position. Figure 2 (left panel) shows serial position curves for the younger children. There was no primacy effect in either condition, and a recency effect occurred only in backward recall. This was confirmed by a two-way analysis of variance (ANOVA), which revealed a significant main effect of order of recall $[F(1,23)=24.4, p<.01]$ and an interaction between recall order and serial position $[F(2,46)=24.6$, $p<.01]$.

Figure 2 shows serial position curves for the older children. Once again, there was recency only in backward recall. For older children, however, there was a strong primacy effect, most notably in the case of forward recall. A two-way ANOVA showed a significant effect of recall order $[F(1,23)=6.46, p<.05]$ and an interaction between order of report and serial position $[F(4,93)=37.9$, $p<.01]$.

\section{Discussion}

The primacy effect for older children and the general superiority of forward report suggest that the older children were actively rehearsing, thereby using a sequentially organized form of storage. Of greater interest, the absence of primacy in the younger children's data suggests that they were not rehearsing, and the superiority of backward report implies that, for them, storage was not organized in a forward temporal sequence.

Although these results follow the predicted pattern, they do not by themselves provide a fully convincing demonstration that young children utilize a visuospatial storage system. To provide such evidence, it is necessary to show more directly that their memory performance is sensitive to further visual or spatial manipulations, in addition to the visual similarity effect already described. The next experiment examined this possibility by investigating the sensitivity of the recency effect found in backward report to different presentation modalities of material used to produce retroactive interference $(\mathrm{RI})$.

\section{EXPERIMENT 3}

Studies of memory in adults have shown that recency can be disrupted by interpolating an irrelevant task between list presentation and recall (see, e.g., Hitch, 1980). The present experiment examined the sensitivity of the recency effect found in children's backward recall of sequences of drawings of familiar objects to either visual or auditory-verbal RI. It was assumed that if younger children store recently presented drawings in a specifically visual store, a subsequent visual task would diminish the recency effect, whereas a subsequent auditory-verbal one would have much less effect. If, on the other hand, older children rely on the articulatory loop to store the names of the drawings, they should be much more sensitive to auditory-verbal RI. This follows from the assumption that auditory-verbal material has automatic access to the ar-
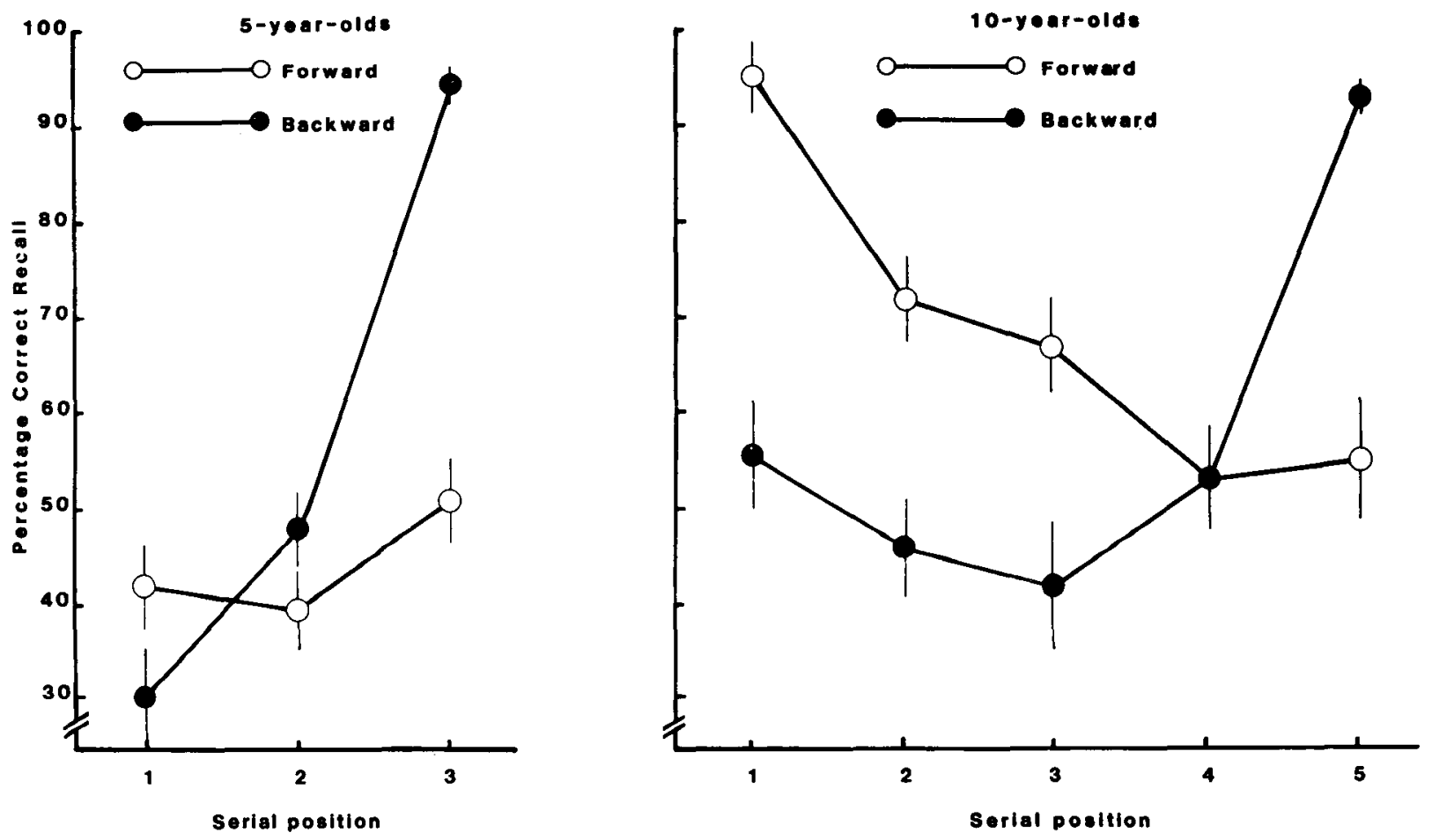

Figure 2. Serial position curves for forward and backward recall in 5-year-olds (left panel) and in 10-year-olds (right panel). 
ticulatory loop (Salamé \& Baddeley, 1982). The extent to which older children are affected by visual RI should give some indication of the degree to which they are also coding visually, in parallel with the assumed preponderance of speech-based coding.

There are many methodological problems with the present type of experiment, not least of which is that of assuring that any differences between interfering tasks are due to their modality as opposed to other factors such as their general level of difficulty (see Clayton \& Warren, 1976). As one precaution against this, the decision components of the visual and auditory-verbal interference tasks were made as similar as possible. Children had to classify a noun or object on the basis of its animacy, with in one case auditory presentation and a verbal response, and in the other visual presentation and manual response. As a second precaution, a subsidiary part of the experiment examined the effects of the two types of interfering task on memory for spoken sequences. This was to see whether patterns of interference were specific to the visual presentation modality or common to both auditory and visual presentation.

\section{Method}

Subjects. One hundred twenty-eight children took part in the study. There were 64 children ( 31 boys and 33 girls) in the younger group. They were aged from 5,0 to $6,6(M=5,8)$. There were 64 children ( 32 boys and 32 girls) in the older group, aged between 10,8 and $11,9(M=11,2)$. The children were from schools in middleclass areas of Manchester.

Materials. A set of 8 items to be remembered and a set of 20 items for interference were used throughout the experiment. The memory items were the control set used in Experiment 1. The interfering items were 10 animals and 10 inanimate items. The animals were selected from the category "four-footed animals" in the Battig and Montague (1969) norms and comprised the 10 highest ranked one-syllable names. The other names were drawn from several other categories and again were the highest ranked one-syllable items. Line drawings of these items were copied from the Peabody Picture Vocabulary Test (Dunn, 1965) and mounted on $9 \times 9 \mathrm{~cm}$ white cards. An additional set of four items was used for training in the memorization task. They were the same items that were used for practice in Experiment 1.

Design. The younger and older children were presented with sequences of three and five items, respectively, to avoid floor and ceiling effects.

There were four subgroups of $\mathbf{1 6}$ children in each age group, balanced as closely as possible by age and sex. Two of these subgroups were assigned to the main experiment involving memory for drawings. The remainder served in the subsidiary study of memory for spoken words. In each case, one subgroup (Group 1) received the control condition and the visual interference condition, and the other (Group 2) served in the control condition and the auditory-verbal interference condition.

In the control condition there was a 4-sec unfilled interval between the end of list presentation and the start of recall. The interference conditions involved a filled delay of the same duration. This was achieved by requiring the younger children to classify a single item and the older children to classify two items. Administration of the control and interference conditions was blocked for each child and counterbalanced across subjects.

Procedure. The children were tested individually in two sessions lasting approximately $10 \mathrm{~min}$ each on separate days. The first ses- sion began with training in the backward recall task using short sequences. The younger children were presented with lists of two items and older children four. In the case of visual presentation of the memory items, each drawing was shown and then turned face down in a row of separate spatial locations. The children allocated to this condition were first given practice in naming the items, as in Experiment 1. With spoken presentation, a set of blank cards was dealt as the experimenter said the items to be remembered. Pilot work showed that this made it easy to convey to the younger children the requirement for recall in backward order. The rate of presentation was one item every $2 \mathrm{sec}$. Spoken recall was prompted as before by the experimenter's pointing to each location in turn, starting with the most recent item. Training in backward recall was continued until performance was correct on two consecutive trials.

Next, the younger children were given practice on the interfering task. In the visual interference condition, two drawings were put face up on the table. One of them showed an animal, the other did not. The child was then given the interference pictures and asked to sort them into two piles, one of animals the other of nonanimals, on top of the two face-up cards. The children allocated to the auditory-verbal interference condition were not shown any drawings. They listened to the experimenter say the name of each item and responded "yes" if it was an animal and "no" if it was not. The children made no mistakes on either of these tasks. The older children were not asked to practice the interfering tasks in this way, since pilot work showed that they understood them readily.

In the final stage of training, each younger and older child was given practice in performing both the memory task and the interference task together, until the experimenter was sure that the child understood and was familiar with the procedure. The interfering task began as soon as list presentation was complete. The younger children classified one drawing or spoken word according to condition, the older children two.

Testing proper was carried out in the second session. The children in the visual presentation condition were first given practice in naming the drawings used in the memory task. All children then performed a block of six trials in each of two conditions, control (4-sec unfilled delay) and interference (either visual or auditoryverbal). Practice was given before each block to ensure that the testing procedure was fully understood.

\section{Results}

Recall performance was scored in terms of the number of items correctly recalled at each serial position. A preliminary check was made to see if levels of performance in the control condition were the same in pairs of subgroups assigned to different types of interference. The seriai position curves were closely similar in all cases, and a series of between-subjects ANOVAs showed that all $F$ s were less than 1 . The results are discussed in two parts, one dealing with the younger children, the other with the older ones.

Younger children. Figure 3 (left panel) shows the serial position curves obtained when the memory materials were drawings. As expected on the basis of the results of Experiment 2, the control condition gave rise to a clear recency effect but no primacy effect. Visual RI abolished this recency effect, whereas auditory-verbal interference appeared to have very little, if any, effect. A withinsubjects ANOVA on data from the visual interference subgroup showed main effects of interference $[F(1,15)=$ $22.9, p<.01]$ and serial position $[F(2,30)=12.4$, $p<.01]$ and a significant interaction $[F(2,30)=12.4$, 
Drawinge

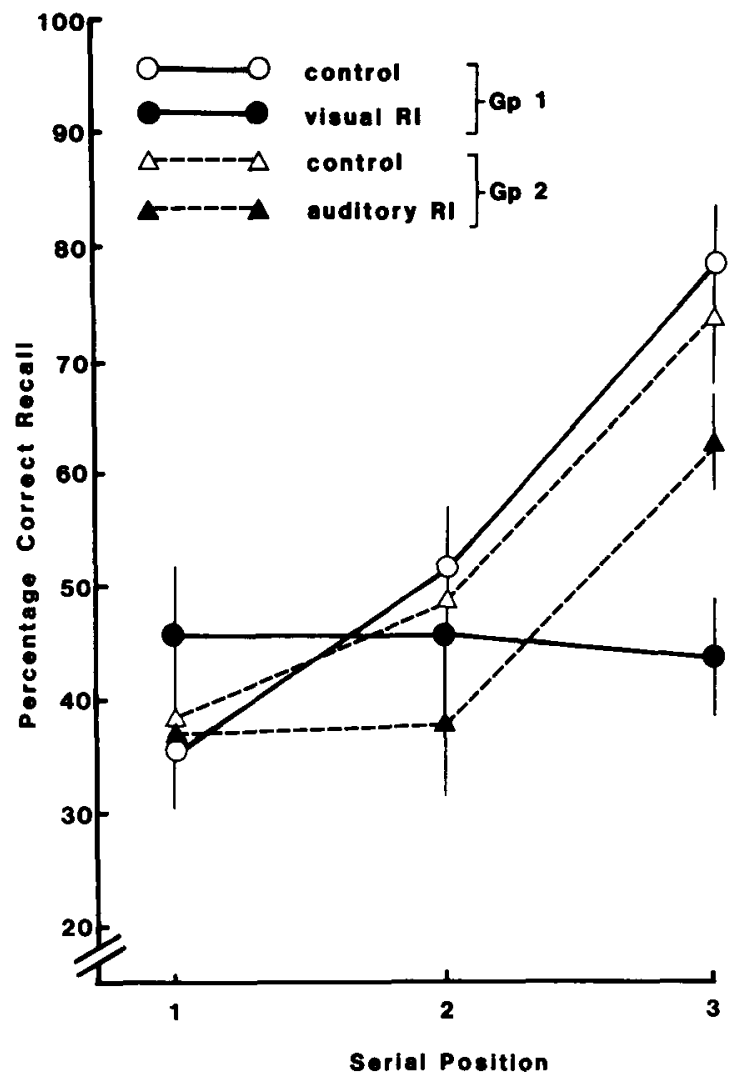

spoken worde

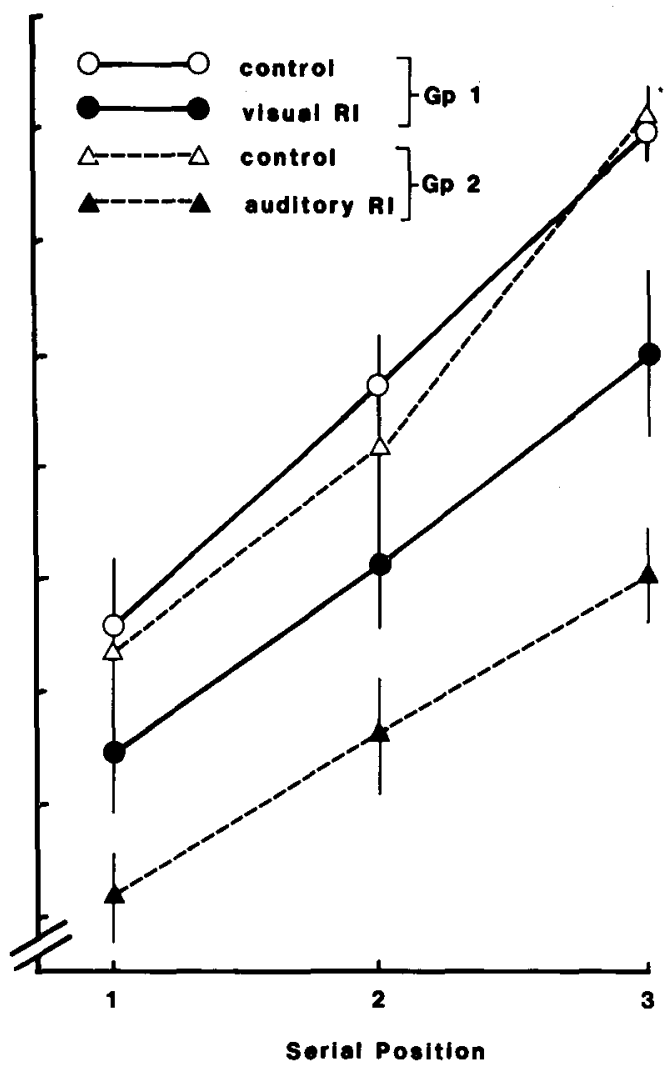

Figure 3. Serial position curves showing the effects of visual and verbal retroactive interference (RI) on 5-year-olds' memory for drawings (left panel) and spoken words (right panel).

$p<.01]$. Further comparisons using Tukey's test showed that visual interference lowered performance on the most recent item but had no effect on the earlier items. A similar analysis of data for the auditory-verbal subgroup showed that only the effect of serial position was significant $[F(2,30)=14.9, p<.01]$. Neither the main effect of interference nor its interaction with serial position was significant.

Figure 3 also shows the serial position curves obtained when the memory items were spoken words. This pattern of results was quite different in that visual interference produced a small overall decrement in recall $[F(1,15)$ $=6.55, p<.05]$ that did not interact with serial position $(F<1)$. In contrast, auditory-verbal interference caused a large decrement in recall $[F(1,15)=58.5$, $p<.01]$ and interacted with serial position $[F(2,30)=$ $4.41, p<.05]$. The interaction corresponds to a slight tendency for recently spoken items to be more sensitive to auditory-verbal interference.

Older children. Figure 4 (left panel) shows the serial position curves obtained when the memory items were drawings. In line with Experiment 2, the control condition gave rise to both primacy and recency effects. Visual RI had only a small disruptive effect $[F(1,15)=5.74$, $p<.05]$, and, although this was limited to final list items, there was no significant interaction with serial position $[F(4,60)=1.88$, n.s. $]$. In contrast, there was a massive effect of auditory-verbal interference $[F(1,15)=31.5$, $p<.01]$ that also interacted significantly with serial position $[F(4,60)=4.21, p<.01]$. Although auditoryverbal interference seems to have lowered performance at all positions, Tukey tests reached significance only on the final two. Thus for older children, memory for drawings is particularly sensitive to auditory-verbal RI, a small amount of which is sufficient to abolish the recency effect. This is in direct contrast with the pattern for younger children.

Figure 4 (right panel) shows the serial position data when the memory items were spoken words. Under control conditions, there was a marked recency effect coupled with some evidence of primacy. Visual RI had no discernible effect, whereas auditory-verbal interference led to a marked diminution of recency. ANOVAs failed to reveal any significant effects associated with visual interference $(F \mathrm{~s}<1)$, but there was a large effect of auditory-verbal interference $[F(1,15)=72.6, p<.01]$, which interacted with serial position $[F(4,60)=11.2$, $p<.011$. Tukey tests showed that the effect of auditoryverbal interference was significant at only the three most recent serial positions. Thus for the older children, un- 

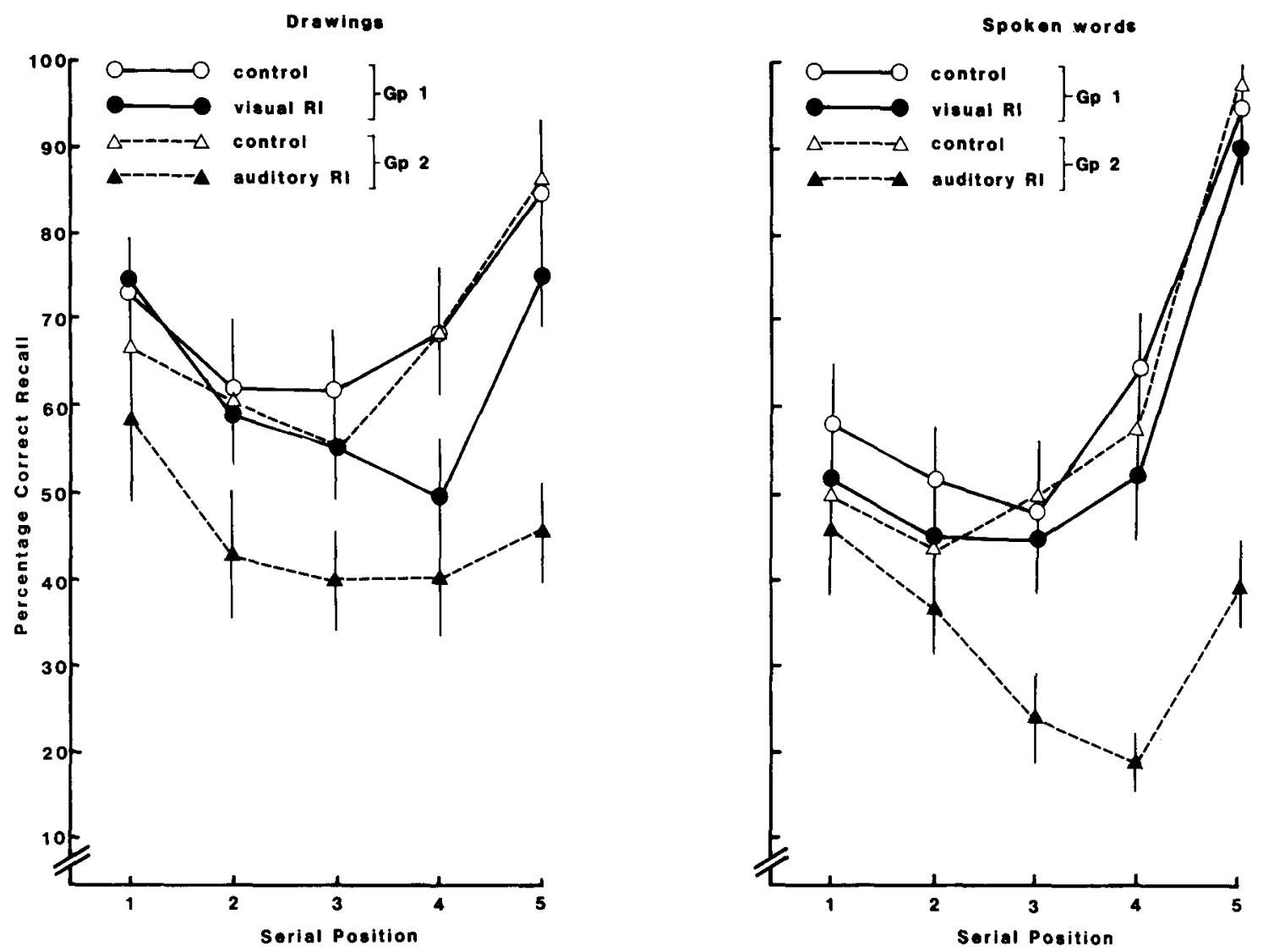

Figure 4. Serial position curves showing the effects of visual and verbal retroactive interference (RI) on 11-year-olds' memory for drawings (left panel) and spoken words (right panel).

like the younger ones, the pattern of sensitivity to interference is broadly similar for both visual and spoken presentation of the memory materials.

\section{Discussion}

The results confirm that the recency effect in memory for drawings in younger children reflects the use of visual memory representations, whereas in older children it derives mostly from the use of auditory-verbal representations. The critical finding is that recency for drawings is disrupted by visual RI in younger children, but is more sensitive to auditory-verbal interference in older ones. The data on memory for spoken materials strengthen this interpretation, since recency in that case was more sensitive to auditory-verbal RI, regardless of children's age. These data demonstrate the modality specificity of the visual interference effect in the younger children, and confirm the ability of the auditory-verbal task to disrupt auditory-verbal memory representations. It is evident that the general pattern of results cannot easily be explained in terms of possible differences in the general difficulty levels of the two interfering tasks. Such an interpretation is ruled out by the differences in RI effects when presentation modality is changed in younger children.

\section{EXPERIMENT 4}

A possible criticism of the interfering tasks used in Experiment 3 is that they required semantic decisions. They may each have involved considerable general processing effort over and above demands on modality-specific resources. A more convincing test would be to see if a less difficult interfering task, involving visuospatial judgments, could also disrupt recency for drawings in younger children. We set out to provide such a test in Experiment 4 . We also attempted to confirm the modality specificity of this simpler visual RI task by assessing its ability to disrupt recency for spoken materials. Groups of 5-year-olds were therefore given either drawings or spoken words to remember, with recall following either a short, unfilled postlist interval or the same amount of time spent performing a simple visual matching task.

\section{Method}

Subjects. The children were 18 boys and 18 girls with a mean age of 5,5 (range 4,11-6,1). They were drawn from two primary schools, one located in a lower-middle-class area and one in a middle-class area of Manchester. They were divided into two groups, matched as closely as possible by age, sex, and school. 
Materials. The memory materials were the drawings that formed the control set in Experiment 1 and their spoken names. The visual interference task involved 14 duplicate pairs of unrelated line drawings of familiar objects.

Design. In general, the design followed closely the relevant part of Experiment 3. Thus the children in one group were presented with three spoken items to recall, and those in the other were shown three drawings. All children served in both the control and visual RI conditions. The RI consisted of a visual matching task; the control was an unfilled interval. Both conditions had a 4-sec postlist delay. The conditions were presented in counterbalanced order in two blocks of six trials. The memory and interference items were freshly randomized for each child and were different on each trial.

Procedure. Details of the procedure follow that for the 5-yearold groups in Experiment 3 except for the nature of the visual intervening task. After presenting the memory materials, the experimenter placed two different pictures face up on the table in front of the child and gave the child a third picture that was identical to one of the other two. The child had to put this third picture on top of the one it matched. Having done this, the experimenter used the method of pointing to overturned or blank cards to obtain spoken recall in reverse serial order.

\section{Results}

Figure 5 shows the serial position curves for the three conditions. Control curves for the two groups are plotted separately. The data confirm that visual interference has

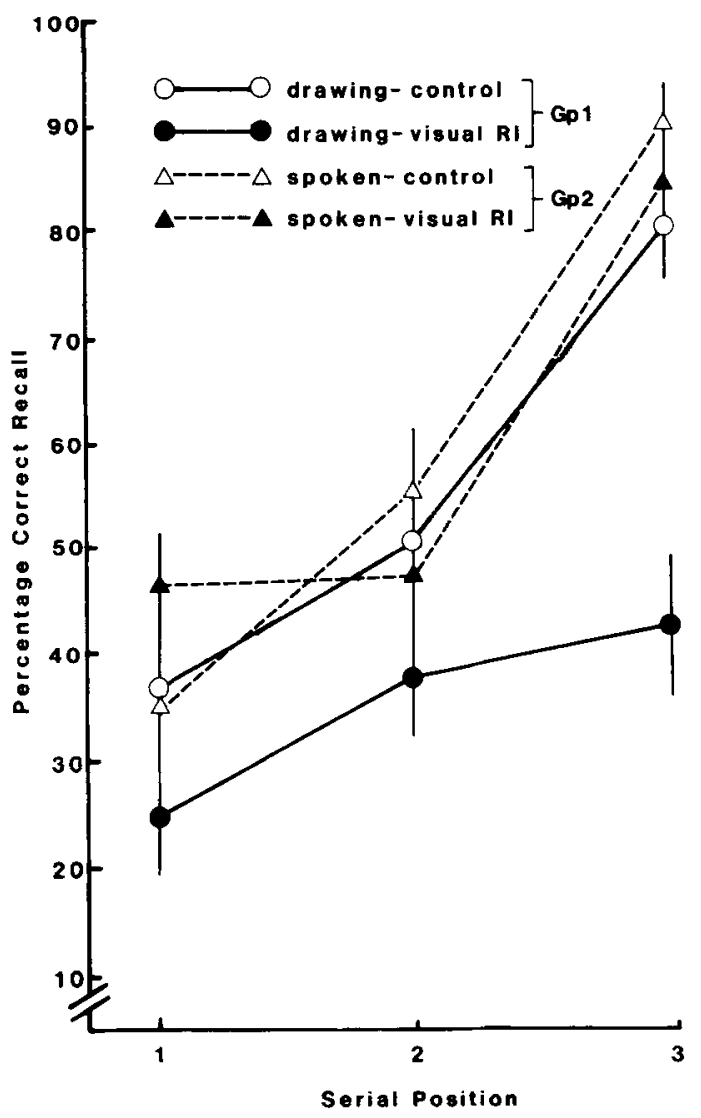

Figure 5. Serial position curves showing the effect of visual retroactive interference (RI) on 5-year-olds' memory for drawings and spoken words. a large effect on recency for drawings, but little, if any, effect on recency for spoken words.

Analysis of variance showed that, in memory for drawings, there were significant effects of serial position $[F(2,34)=24.8, p<.01]$ and visual interference $[F(1,17)=17.8, p<.01]$. There was also a significant interaction between interference and serial position $[F(2,34)=13.0, p<.01]$. Tukey's tests showed that the disruption by interference was significant at positions 3 and 2 but not at position 1. A similar analysis of the results for spoken presentation showed a significant recency effect $[F(2,34)=55.6, p<.01]$, but no main effect of interference $(F<1)$. The interaction between interference and serial position, however, was significant $[F(2,34)=4.78, p<.05]$, but Tukey tests failed to find significant differences at any individual serial position. Inspection of Figure 5 shows that this interaction relates to very small differences in performance when compared with the data for drawings.

To make a direct comparison of the effects of interference on memory for drawings and spoken words, data from the final serial position were entered into a two-way ANOVA with modality as the between-subjects factor and presence or absence of visual interference as the withinsubjects factor. The interaction was highly significant $[F(1,34)=20.8, p<.01]$, confirming that visual $\mathrm{RI}$ is modality specific. A planned comparison showed that performance in the two control conditions did not differ $[F(1,34)=3.39, p>.05]$, showing that the interaction cannot be attributed to differences in the level of acquisition of spoken and visual lists.

\section{Discussion}

The results of this study are clear-cut. They demonstrate that the recency effect in young children's memory for drawings is disrupted by visual RI comprising a simple visual matching task. They also demonstrate that the disruption is modality specific since the same task had, by comparison, very little effect on memory for spoken words. A comparison of Figures 3 and 5 confirms our interpretation of the difference in the RI tasks used in Experiments 3 and 4 . The controls are comparable, as they should be, but the present RI task has much less effect on memory for words and a smaller effect on the shape of the serial position curve for drawings.

Taking Experiments 3 and 4 together, it is obviously very difficult to try to explain the total pattern of RI effects in terms of differences in the general level of difficulty of the postlist tasks. It might, however, be objected that the contrast we have obtained is one between auditory-verbal and abstract memory codes, and that what we have shown is that younger children remember drawings on the basis of abstract rather than specifically visual memory representations. We wish to argue strongly against such an interpretation. In the first place, it is difficult to see any good reason for supposing that the visual interfering tasks would be any more likely than the 
auditory-verbal tasks to disrupt abstract representations. Second, the proposition would seem to stand in the face of the usual view that it is older and not younger children who are more likely to make use of abstract memory representations.

\section{EXPERIMENT 5}

The final experiment examined the relationship between the effects of visual RI and those of visual similarity on young children's memory for drawings. Two contrasting possibilities were entertained. According to the first and simpler of the two possibilities, both manipulations disrupt a common mechanism within visual working memory. According to this view, recently presented items should be the ones that are particularly sensitive to visual similarity, since these are the items that are most affected by visual RI. There should, therefore, be an interaction between the size of the visual similarity effect and serial position. Furthermore, the presence of visual RI should evidently reduce the size of the visual similarity effect. This amounts to another interaction such that the effect of one manipulation is reduced in the presence of the other.

The second possibility assumes that the two manipulations do not converge on a common mechanism. According to this view, there is no reason to expect recent items rather than any others to be the ones most affected by visual similarity. Furthermore, visual RI and visual similarity should behave independently and have additive rather than interactive joint effects on recall. One interesting way in which this might occur would be if RI and similarity affected separate modes of accessing material stored in visual working memory. Accordingly, Experiment 5 examined the simultaneous effects of visual similarity and visual RI on serial position curves for recall using a factorial design.

\section{Method}

Subjects. Twenty-four children ( 12 boys and 12 girls) took part in the experiment. Their mean age was 5,5 (range 4,10-5,9). They were from two primary schools in a middle-class suburb of Manchester.

Materials. The memory materials were taken from the two sets of items used in the control and visually similar conditions of Experiment 1 . The interfering materials were taken from $20 \mathrm{dupli}-$ cate pairs of line drawings of familiar objects. They were unrelated to one another and the memory materials. The practice materials were the same as in Experiment 1.

Design. Each child served in all four conditions derived from combining similarity of the memory materials and the presence or absence of visual RI. Each condition was run in a series of six consecutive trials. Presentation of the two interference conditions was blocked and counterbalanced across children. Within each block, half the children began with six trials involving dissimilar drawings and half began with visually similar drawings. The sequences of drawings were freshly randomized for each child.

Procedure. The training and testing procedures were the same as in the visual presentation conditions of Experiment 4. Children were tested in two sessions on consecutive days, each session lasting about $10 \mathrm{~min}$.

\section{Results}

Figure 6 shows the results in the form of serial position curves. As expected, recency was present in the control condition and was virtually abolished by visual RI. It seems, however, that the visual similarity effect is not confined to recent items and is not reduced by visual RI. A three-way ANOVA revealed significant main effects of serial position $[F(2,46)=81.9, p<.01]$ and visual interference $[F(1,23)=101.2, p<.01]$, and the expected two-way interaction between interference and position $[F(2,46)=34.3, p<.01]$. The main effect of materials was significant $[F(1,23)=33.4, p<.01]$, but did not interact with either interference $(F<1)$ or serial position $[F(2,46)=3.98]$. The three-way interaction was not significant $(F<1)$.

\section{Discussion}

The results are quite clear in showing that visual RI does not reduce the size of the visual similarity effect, nor is visual recency reduced for visually similar materials. It must be concluded, therefore, that the effects of these two variables do not have the same basis in visual working memory. It seems probable that they reflect separate modes of accessing stored material. This would be consistent with a model of the recency effect in adult sub-

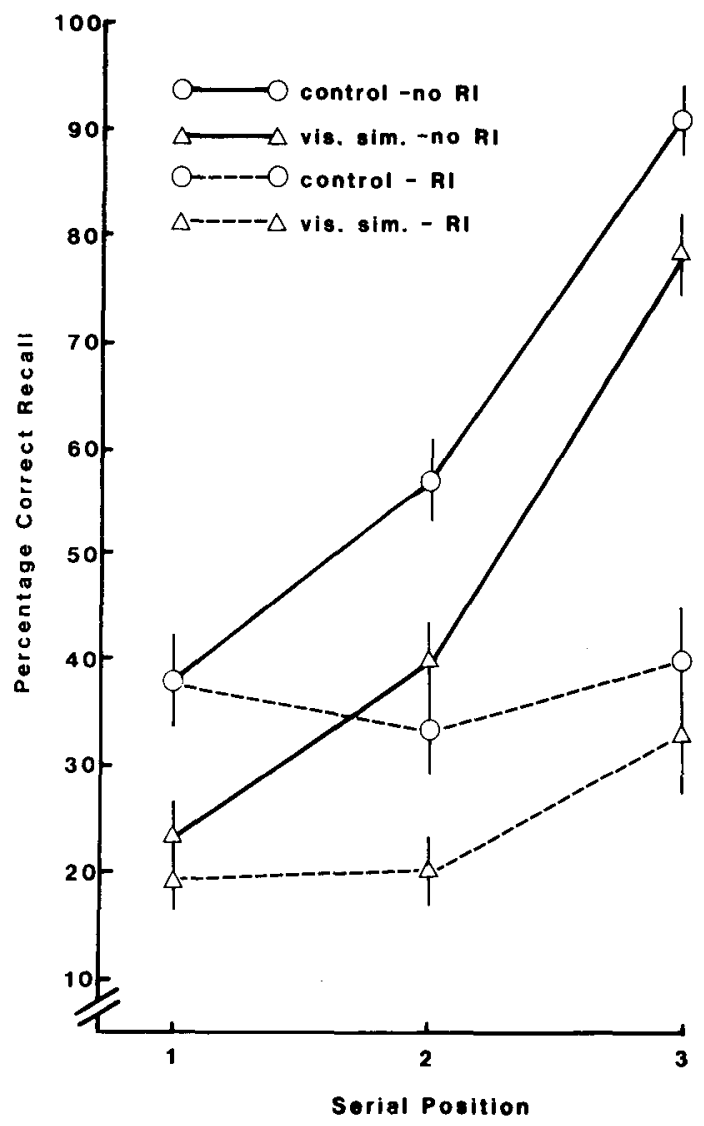

Figure 6. Serial pasition curves showing the effects of visual similarity and visual retroactive interference $(R I)$ on 5 -year-alds' memory for drawings. 
jects, which maintains that recency is due to a general retrieval strategy whereby the memory traces of individual items are accessed via ordinal position cues (Baddeley \& Hitch, 1977; Hitch, 1980). Young children may apply this retrieval strategy to the contents of visual working memory. The entry of subsequent information into the store, due to visual RI, would alter the ordinal position cues associated with the final items in the memory list and thus would disrupt recency. Nonvisual RI would not disrupt ordinal cues for visual inputs and would hence be relatively ineffective in reducing recency. According to this model, accessing or locating a trace via ordinal cues in visual working memory is distinguishable from the process of identifying or reading out the content of the trace. In discussing Experiment 1 it was suggested that readout involves reconstructing what the item must have been on the basis of what trace information remains after partial forgetting. If visual similarity among the items disrupts this second process of readout, it should of course be independent of whether or not access to the trace involves using the recency strategy. Implicit in this argument, of course, is the idea that traces can be accessed by other routes that do not depend on the use of ordinal cues.

\section{GENERAL DISCUSSION}

The effects of visual similarity, order of report, and visual RI give consistent support to the hypothesis that young children use a visual component of working memory to represent sequences of drawings in immediate recall tasks. The most convincing evidence comes from the effects of visual similarity and visual RI, since these are specifically visual manipulations. The effects of order of report permit a wider range of interpretations, so they do not make such a strong case. It is, however, relevant that these effects fit in with the general pattern. We infer that young children's tendency to use visual working memory for visual materials is a strong one since it persists in spite of the requirement in the present tasks for verbal report and the retention of information about temporal order. Other aspects of the data are consistent with previous suggestions that, in the very same tasks, older children are much more dependent on using the articulatory loop component of working memory to store verbal labels for drawings.

The results raise a number of issues that call attention to some unresolved questions. First, the differences between older and younger children are confounded with sequence length in the present experiments. It is therefore possible that older children's use of subvocal rehearsal was encouraged by giving them more items, whereas that of younger children was discouraged by giving them fewer. We consider the latter especially unlikely, since young children's memory for visual sequences of as many as eight items shows no primacy effect (Atkinson et al., 1964). It would, however, be important to confirm that the present conclusions are not restricted to the sequence lengths employed here.

Second, since only two ages were used, it is not possible to comment on the developmental course of dependence on different modalities of storage in working memory. More specifically, we need to know more about how the increased use of auditory-verbal storage comes about, and what happens to the use of visual storage. This is evidently a topic for further experimentation. One important question is why young children do not use auditory-verbal coding for visual materials. One possibility is that they have insufficient information processing capacity to carry out the necessary stimulus recoding operations; another is that they lack appropriate metamemory (Flavell \& Wellman, 1977), the subjective knowledge that such recoding may be advantageous. Another question is whether children merely switch from one preferred encoding strategy to another with increasing age. This would seem the simplest interpretation of the present studies, since there was very little evidence that older children were sensitive to either visual similarity or visual RI. However, studies recently completed in our laboratory by Michael Woodin reveal that there is a small visual component in older children's recall. This suggests that the developmental pattern is one of an increase in the number of codes available in working memory rather than the substitution of one type of coding for another, and is consistent with current ideas about multiple coding in adults (see Paivio, 1971).

It is important to emphasize that the developmental differences revealed here are specific to tasks involving memory for visual materials. We noted earlier evidence that young children rely on auditory-verbal coding to store spoken materials in otherwise similar tasks (Hitch \& Halliday, 1983), and this is confirmed by Experiment 3 in the present series. It seems necessary, therefore, to take modality differences into account in any analysis of the development of memorization processes, a point that does not appear to be generally appreciated in the literature. If the capacity for both visual and auditory-verbal coding is already present in younger children, then perhaps the major developmental change in immediate memory is in the conditions whereby the auditory-verbal rehearsal system is called into use, not simply the development of rehearsal per se. Indeed, perhaps the most intriguing question raised by our research is why older children are more reliant on auditory-verbal encoding. The present results do not distinguish between a maturational process and one that is fostered by some aspect of experience, such as exposure to formal education. It would clearly be interesting to know, for example, whether 10-year-olds who have not undergone formal schooling would show the same pattern of results that we have observed here.

The immediate theoretical background to the present investigations was the Baddeley and Hitch (1974) model of adult working memory (see also Baddeley, 1986). The data are broadly consistent with the model insofar as they 
imply a distinction between auditory-verbal and visual components of temporary information storage, with ease of access to the former critically dependent upon input modality. However, given the exploratory nature of the present investigation, it is difficult to establish links between the properties of the visual storage system identified here in young children and the corresponding component of adult working memory. Thus, the data from young children say nothing about the nature or existence of control processes specific to visual information, nor about possible differences between spatial and visual interference thought to be important in the case of adult visual working memory (Baddeley \& Lieberman, 1980). This is, of course, partly due to the use, so far, of nonoverlapping methodologies. Interestingly, however, there is some evidence to suggest that young children's immediate memory for drawings is unaffected by a concurrent tapping task, suggesting that they are not engaging in attention-demanding control processes (Hitch \& Halliday, 1983). We wish to suggest, therefore, that the present experiments focus on the passive storage component of visual working memory, common to both children and adults. Our results imply that the immature system has a small capacity, stores items in terms of their visual characteristics such as shape and orientation, and contains some representation of their recency of encounter. We have suggested also that information in visual working storage is accessed by at least two separate modes, locating traces via recency or other cues, and reading off the contents of individual traces.

Such a passive memory system may perhaps serve the function of keeping track of the identity and location of recently perceived objects that are currently out of view. If so, it may seem unclear why its capacity should appear to be so limited. However, it seems probable that other, more suitable experimental tasks may lead to higher, more realistic capacity estimates than the present data. Given the far-reaching importance of being able to keep track, it is not surprising that the basis of this ability is already well established in young children. We presume that the ability to operate upon and transform representations in visual working memory develops later than the passive store. We speculate, therefore, that adult visual working memory comprises much the same store as has been identified here, but in conjunction with a wider range of control processes.

Finally, it is interesting to note that the present results have implications for theories that attempt to understand cognitive development in terms of changes in the efficiency of a central system for temporary storage and information processing (Case, 1984; Halford \& Wilson, 1980; Pascual-Leone, 1970). Such theories make the implicit assumption that working memory comprises a single, undifferentiated resource. The present experiments lead to the suggestion that a more accurate account of development will separate out the changing patterns of use of modality-specific subsystems in working memory associated with different ways of representing temporary information.

\section{REFERENCES}

Atkinson, R. C., Hansen, D. N., \& Bernbach, H. A. (1964). Shortterm memory with young children. Psychonomic Science, 1, 255-256. Baddeley, A. D. (1986). Working memory. Oxford: Clarendon Press. BADDEley, A. D., \& Hitch, G. J. (1974). Working memory. In G. H. Bower (Ed.), The psychology of leaming and motivation (Vol. 8, pp. 47-90). New York: Academic Press.

BADDEley, A. D., \& Hitch, G. J. (1977). Recency re-examined. In S. Dornic (Ed.), Attention and performance (Vol. 6, pp. 647-665). New York: Academic Press.

Baddeley, A. D., \& Lieberman, K. (1980). Spatial working memory. In R. Nickerson (Ed.), Attention and performance (Vol. 8, pp. 521539). Hillsdale, NJ: Erlbaum.

Battig, W. F., \& Montague, W. E. (1969). Category norms of verbal items in 56 categories: A replication and extension of the Connecticut category norms. Journal of Experimental Psychology Monographs, 80(3, Pt. 2).

Broadbent, D. E., \& Broadbent, M. H. P. (1981). Recency effects in visual memory. Quarterly Journal of Experimental Psychology, 33A, $1-15$.

Brown, R. M. (1977). An examination of visual and verbal coding processes in preschool children. Child Development, 48, 38-45.

Carroll, J. B., Davies, P., \& Richman, B. (1971). Word frequency book. New York: American Heritage.

CASE, R. M. (1984). The process of stage transition: A neo-Piagetian view. In R. J. Sternberg, (Ed.), Mechanisms of cognitive development (pp. 19-44). New York: Freeman.

Clayton, K. N., \& WARREN, M. W. (1976). Methodological problems with the use of the retroactive interference design to infer what is stored. Memory \& Cognition, 4, 237-243.

COHEN, R. L., \& GRANSTROM, K. (1970). Reproduction and recognition in short-term visual memory. Quarterly Journal of Experimental Psychology, 22, 450-457.

ConRad, R. (1965). Order errors in immediate recall of sequences. Journal of Verbal Leaming \& Verbal Behavior, 4, 161-169.

ConRaD, R. (1967). Interference or decay over short retention intervals? Journal of Verbal Learning \& Verbal Behavior, 6, 49-54

ConRaD, R. (1971). The chronology of the development of covert speech in children. Developmental Psychology, 5, 398-405.

Dunn, L. M. (1965). Peabody picture vocabulary test. Circle Pines, MN: American Guidance Service.

Flavell, J. H., \& Welluman, H. M. (1977). Metamemory. In R. V. Kail \& J. W. Hagen (Eds.), Perspectives on the development of memory and cognition (pp. 3-34). Hillsdale, NJ: Erlbaum.

HaGen, J. W., \& KaIL, R. V. (1973). Facilitation and distraction in shcrt-term memory. Child Development, 39, 113-121.

Hagen, J. W., \& Stanovich, K. G. (1977). Memory: Strategies of acquisition. In R. V. Kail \& J. W. Hagen (Eds.), Perspectives on the development of memory and cognition (pp. 89-111). Hillsdale, NJ: Erlbaum.

HALFORD, G. S., \& WILSON, W. H. (1980). A category theory approach to cognitive development. Cognitive Psychology, 12, 356-411.

Hayes, D. S., \& SCHulze, S. A. (1977). Visual encoding in preschoolers' serial retention. Child Development, 48, 1066-1070. Hгтсн, G. J. (1980). Developing the concept of working memory. In G. Claxton (Ed.), Cognitive psychology: New directions (pp. 154-196). London: Routledge \& Kegan Paul.

Hirch, G. J., \& Halliday, M. S. (1983). Working memory in children. Philosophical Transactions of the Royal Society London Series $B$, 302, 325-340.

KAIL, R. V. (1984). The development of memory in children (2nd ed.). New York: Freeman. 
KingSLEY, P. R., \& HAGEN, J. W. (1969). Induced versus spontaneous rehearsal in short-term memory in nursery school children. Developmental Psychology, 1, 40-46.

Nicolson, R. (1981). The relation between memory span and processing speed. In M. P. Friedman, J. P. Das, \& N. O'Connor (Eds.), Intelligence and learning (pp. 179-183). New York: Plenum Press.

O'Connor, N., \& Hermelin, R. T. (1976). Backward and forward recall by deaf and hearing children. Quarterly Journal of Experimental Psychology, 28, 83-92.

O'Connor, N., \& Hermelin, R. T. (1978). Seeing and hearing and space and time. London: Academic Press.

Paivio, A. (1971). Imagery and verbal processes. New York: Holt, Rinehart \& Winston.
Pascual-Leone, J. A. (1970). A mathematical model for the transition rule in Piaget's developmental stages. Acta Psychologica, 32, 301-345.

Philuips, W. A., \& Christie, D. F. M. (1977). Components of visual memory. Quarterly Journal of Experimental Psychology, 29, 117-133.

Salamé, P., BadDeley, A. D. (1982). Disruption of short-term memory by unattended speech: Implications for the structure of working memory. Journal of Verbal Learning \& Verbal Behavior, 21, 150-164.

(Manuscript received May 28, 1987;

revision accepted for publication September 16, 1987.)

\section{Notice}

\section{Third Symposium on Progress in Research on Brain and Behavior "Advances in Research on Cerebral Laterality Effects" \\ Toledo, Ohio \\ April 8-9, 1988}

The Third Symposium on Progress in Research on Brain and Behavior, sponsored by the University of Toledo Department of Psychology and the University of Toledo Alumni Foundation, will be held in the Driscoll Center for Continuing Education on the University of Toledo campus on April 8 and 9, 1988.

The theme for this symposium is Advances in Research on Cerebral Laterality Effects. Invited papers will be presented on advances in our knowledge of laterality effects with topics including research in the areas of anatomy, electrophysiology, neuropsychology, and behavior.

The participants for this symposium are M. P. Bryden, A. S. Gevins, C. R. Hamilton, C. Hardyck, J. B. Hellige, M. Kinsbourne, S. M. Kosslyn, J. Levy, W. F. McKeever, D. Molfese, J. Sergent, J. Ward, S. Witleson, and F. Wood.

For registration and other information, contact Fred Kitterle, Department of Psychology, University of Toledo, Toledo, Ohio 43606 (Phone: (419) 537-2722). 